\title{
Studies on conjugation of Spirogyra using monoclonal culture
}

\author{
Hisato Ikegaya $\cdot$ Takuto Nakase $\cdot$ Kazuyoshi Iwata \\ Hideaki Tsuchida $\cdot$ Seiji Sonobe $\cdot$ Teruo Shimmen
}

Received: 9 May 2011/Accepted: 12 September 2011/Published online: 18 October 2011

(c) The Author(s) 2011. This article is published with open access at Springerlink.com

\begin{abstract}
We succeeded in inducing conjugation of Spirogyra castanacea by incubating algal filaments on agar plate. Conjugation could be induced using clone culture. The scalariform conjugation was generally observed, while lateral conjugation was rarely. When two filaments formed scalariform conjugation, all cells of one filament behaved as male and those of other filament did as female. Very rarely, however, zygospores were formed in both of pair filaments. The surface of conjugation tube was stained with fluorescently labeledlectins, such as Bandeiraea (Griffonia) simplicifolia lectin (BSL-I) and jacalin. BSL-I strongly stained the conjugation tubes, while weakly did the cell surface of female gamete first and then that of male gamete. Jacalin stained mainly the conjugation tubes. Addition of jacalin inhibited the formation of papilla, suggesting some important role of jacalin-binding material at the initial step of formation of the conjugation tubes.
\end{abstract}

Keywords Spirogyra $\cdot$ Conjugation $\cdot$ Zygote $\cdot$ Lectin

$\begin{array}{ll}\text { Abbreviations } \\ \text { APW } & \text { Artificial pond water } \\ \text { HEPES } & \begin{array}{l}N \text {-2-hydroxyethylpiperazine- } N \text { '-2- } \\ \text { ethanesulfonic acid }\end{array}\end{array}$

H. Ikegaya $(\bowtie)$

Pioneering Research Unit for Next Generation,

Kyoto University, Uji, Kyoto 611-0011, Japan

e-mail: h-ikegaya@iss.iae.kyoto-u.ac.jp

\section{H. Ikegaya}

Institute of Sustainability Science, Kyoto University,

Uji, Kyoto 611-0011, Japan

T. Nakase $\cdot$ K. Iwata $\cdot$ H. Tsuchida $\cdot$ S. Sonobe $\cdot$ T. Shimmen Graduate School of Life Science, University of Hyogo,

Harima Science Park City, Ako-gun, Hyogo 678-1297, Japan
BSL-I Bandeiraea (Griffonia) simplicifolia lectin I

BSL-II Bandeiraea (Griffonia) simplicifolia lectin II

Con A Concanavalin A

DBA Dolichos biflorus agglutinin

DSL Datura stramonium lectin

ECL Erythrina cristagalli lectin

LEL Lycopersicon esculentum (tomato) lectin

Jacalin Lectin isolated from Artocarpus integrifolia (jackfruit) seeds

PHA-E Phaseolus vulgaris erythroagglutinin

PHA-L Phaseolus vulgaris leucoagglutinin

PNA Peanut agglutinin

PSA Pisum sativum agglutinin

RCA I Ricinus communis agglutinin I

SBA Soy bean agglutinin

SJA Sophora japonica agglutinin

STL Solanum tuberosum (potato) lectin

UEA I Ulex europaeus agglutinin I

VVL Vicia villosa lectin

WGA Wheat germ agglutinin

Glc D-glucose

Gal D-galactose

Man Mannose

GlcNAc $\quad N$-acetyl-D-glucosamine

GalNAc $N$-acetyl-D-galactosamine

\section{Introduction}

Spirogyra is one of the most popular Zygnemataceae and its conjugation process is generally introduced in text books. Sexually competent cells recognize each other and conjugation starts by formation of papilla. After elongation of the protrusion, two cells are connected by a conjugation 
tube and a zygote is finally formed. Two types of conjugation have been reported in Spirogyra. (1) Two filaments align and conjugation tubes are formed between cells of partner filaments. Because of similarity to a ladder, this is called scalariform conjugation. This type is generally observed in genus Spirogyra. (2) Neighboring cells in a single filament conjugate and this type is called lateral conjugation (Lloyd 1924, 1926a, b). Although conjugation of Spirogyra is a well known phenomenon, little is understood about its detailed processes and mechanism, because of difficulty in reproducible induction of conjugation in the laboratory. Therefore, many analyses have been carried out using filaments collected from the native habitats (Saunders 1932; Sasaki et al. 1972; Jordan 1974; Ogawa 1982; Hull et al. 1985). On the other hand, artificial induction of conjugation using Spirogyra cultured in the laboratory has been examined (Allen 1958, Grote 1977, Yamashita and Sasaki 1979, Simons et al. 1984). Allen (1958) succeeded in completing the life cycle of Spirogyra in the laboratory and found conjugation in her culture. Grote (1977) succeeded in initiation and completion of the sexual process in $S$. majuscula Kützing by nitrogen depletion. The role of nitrogen depletion and light intensity were suggested as key factors for inducing conjugation (Yamashita and Sasaki 1979; Simons et al. 1984). Yamashita and Sasaki (1979) found that a high C/N ratio produced by depletion of nitrogen compounds seemed to be needed for the induction of the mating process in Spirogyra. Furthermore, they suggested that light may have a role in accumulation of intracellular carbohydrates, mainly starch, which was necessary for the formation of mature zygote. Despite these works, artificial induction of conjugation has not been useful, because of low reproducibility.

We have been engaged in rhizoid differentiation of Spirogyra (Inoue et al. 1999, 2002; Yamada et al. 2003; Yoshida et al. 2003, 2006, 2008; Yoshida and Shimmen 2007, 2009; Ikegaya et al. 2004, 2008a, b). Randhawa (1959) discussed similarity between rhizoid formation and conjugation process; both result from a contact stimulus. Contact of the cell end to the substratum is essential for differentiation of rhizoid (Nagata 1973; Ikegaya et al. 2008b). At the beginning of rhizoid formation, a papilla is formed and elongates via tip growth (Nagata 1973). Conjugation also starts via formation of papilla. It seems that the conjugation tube elongate via tip growth, although not demonstrated. Based on such background, we were interested in studies on conjugation of Spirogyra. However, difficulty of induction of conjugation hampered this project. Recently, we succeeded in inducing conjugation with high efficiency by incubating algal filaments on agar plate. It was suggested that our method is useful for elucidating the mystery of conjugation in Spirogyra. We could study the process of conjugation using clone culture. Presence of the extracellular glyco-proteinaceous materials in the cell wall of conjugation tube of Spirogyra sp. have been reported (Cheli and De Vecchi 1989). In order to identify the extracellular material, we examined staining with fluorescently labeled lectins. In addition, we examined the effect of lectins on formation of conjugation tubes.

\section{Materials and methods}

Plant materials

Spirogyra castanacea G. C. Couch was collected from a stream near the Harima Kohto campus of University of Hyogo and axenic culture was established by Naoko Inoue in 1995 (Inoue et al. 1999). Later, this was identified to be S. castanacea by H. Ikegaya according to monographs (Yamagishi 1977; Kadlubowska 1984). Axenic culture was kept on either closterium medium (Ichimura 1971) or artificial pond water (APW: $0.1 \mathrm{mM} \mathrm{KCl}, 0.1 \mathrm{mM} \mathrm{CaCl} 2,1 \mathrm{mM} \mathrm{NaCl}, 1 \mathrm{mM}$ HEPES-Na, pH 7.0) under a $12 \mathrm{~h}$ light (fluorescent lamps)$12 \mathrm{~h}$ dark regime at $23^{\circ} \mathrm{C}$. The light intensity was $90 \mu \mathrm{mol} \mathrm{m}{ }^{-2} \mathrm{~s}^{-1}$. S. fuluviatilis Hilse was collected from a pond in Joyo, Kyoto and have been maintained in the laboratory (Iwata 1995; Iwata and Itoh 1998; Iwata et al. 2001). Cultivation of $S$. fuluviatilis in our laboratory started from 2005 using slightly modified Reichart's medium (Nagata 1973) and later closterium medium.

\section{Clone culture}

Single algal filament of $S$. castanacea was isolated from the axenic culture under a dissecting microscope (VB-S20, Keyence, Osaka, Japan). It was transferred to the fresh closterium medium and cultured as described above.

Induction of conjugation

Agar powder (Wako, Osaka, Japan) was suspended in APW $1 \%(\mathrm{w} / \mathrm{v})$ and solubilized by heating. Agar plate was prepared in Petri dish. On the other hand, about 100 filaments were rinsed with APW for $5 \mathrm{~min}$. They were transferred on the agar plate and incubated at $23^{\circ} \mathrm{C}$ under a $12 \mathrm{~h}$ light (fluorescent lamps)-12 h dark cycle for 4 days. The light intensity was $90 \mu \mathrm{mol} \mathrm{m} \mathrm{m}^{-2} \mathrm{~s}^{-1}$. Conjugating filaments on agar plate were transferred on slide glass and observed under a microscope (Axioskop 2, Zeiss, Tokyo, Japan). Photographs were taken with a CCD camera (VB-7010, Keyence, Osaka, Japan).

Effect of nitrogen and other factors on the conjugation

About 100 filaments were incubated on agar plate prepared using either APW supplemented with $1 \mathrm{mM} \mathrm{KNO}_{3}$ or 
closterium medium at $23^{\circ} \mathrm{C}$ under a $12 \mathrm{~h}$ light (fluorescent lamps)-12 h dark cycle for 4 days The light intensity was $90 \mu \mathrm{mol} \mathrm{m} \mathrm{m}^{-2} \mathrm{~s}^{-1}$. When papilla was observed under the microscope, we judged that the cell started conjugation. Results were presented as a ratio of filaments started formation of conjugation tube to the total number of filaments.

\section{Lectin staining}

Lectins labeled with fluorescein were commercially obtained (Vector Laboratories, Inc. Burlingame USA). Following lectins were used: Bandeiraea (Griffonia) simplicifolia lectin I (BSL-I), Bandeiraea (Griffonia) simplicifolia lectin II (BSL-II), concanavalin A (Con A), Dolichos biflorus agglutinin (DBA), Datura stramonium lectin (DSL:), Erythrina cristagalli lectin (ECL), Lycopersicon esculentum (tomato) lectin (LEL), lectin isolated from Artocarpus integrifolia (Jackfruit) seeds (jacalin), Phaseolus vulgaris erythroagglutinin (PHA-E), Phaseolus vulgaris leucoagglutinin (PHA-L), peanut agglutinin (PNA), Pisum sativum agglutinin (PSA), Ricinus communis agglutinin I (RCA I), soy bean agglutinin (SBA), Sophora japonica agglutinin (SJA), Solanum tuberosum (potato) lectin (STL), Ulex europaeus agglutinin I (UEA I), Vicia villosa lectin (VVL), wheat germ agglutinin (WGA). They were diluted in APW (final concentration: $10 \mu \mathrm{g} / \mathrm{ml}$ ) and filaments were stained for $15 \mathrm{~min}$ at $23^{\circ} \mathrm{C}$. After washing with APW, they were observed under a fluorescence microscope (Axioskop 2, Zeiss, Tokyo, Japan). Photographs were taken with a CCD camera (VB-7010, Keyence, Osaka, Japan).

\section{Effect of lectins on conjugation}

About 100 filaments were incubated in APW supplemented with either $1 \mu \mathrm{g} / \mathrm{ml}$ BSL-I, Con A, jacalin, RCA-I, SBA, or WGA at $23^{\circ} \mathrm{C}$ under a $12: 12 \mathrm{~h} \mathrm{~L}-\mathrm{D}$ cycle for 1 day, and then they were transferred on agar plate supplemented with the same lectin and incubated at the same conditions 4 days. When papilla was observed, we judged that the cell started conjugation. Results were presented as a ratio of filaments started formation of conjugation tube to the total number of filaments. Formation of zygospores was also analyzed in the same way.

\section{Results and discussion}

Conjugation of Spirogyra has been reported to be induced by lowering nitrogen content or depletion (Grote 1977; Yamashita and Sasaki 1979; Simons et al. 1984). Therefore, we first tried to induce conjugation by depleting nitrogen from the culture medium. However, this was unsuccessful. Grote (1977) reported that conjugation was induced in pure inorganic closterium medium and that $\mathrm{pH}$ value was important. Although we incubated the algal filaments in the medium of various $\mathrm{pH}$, conjugation was not induced. In addition, other trials, various temperatures and depletion of various nutrients, were unsuccessful. It has been reported that conjugation was induced by incubating algal filaments under continuous illumination in some species of Spirogyra (Yamashita and Sasaki 1979). However, our materials did not show conjugation, even when filaments were incubated without nitrogen source under continuous illumination for 2 weeks. After above various trials, we finally succeeded in inducing conjugation by incubating filaments on agar plate prepared using APW at $23^{\circ} \mathrm{C}$ under a $12: 12-\mathrm{h}$ L-D cycle for 4 days. Rod-shaped rhizoid was also formed at the distal end of terminal cells during the incubation. When filaments on agar plate were incubated in the dark, the conjugation phenomenon was not induced. Allen (1958) has reported that conjugation was induced by incubation on agar plate. She maintained a stock culture using Pringsheim's soilwater medium (Pringsheim 1946) under a 16 h light (cool white fluorescent tube) $-8 \mathrm{~h}$ dark regime at about $20^{\circ} \mathrm{C}$. For induction of mating, several filaments were transferred onto $1.5 \%$ Difco agar prepared using distilled water and incubated at about $20^{\circ} \mathrm{C}$ under a 16:8-h L-D cycle. After incubation for a few days, zygospores were formed on agar plate. Although the light condition and temperature during incubation were different, Allen's method (1958) was fundamentally the same to our method. We further analyzed the factors responsible for conjugation induction on agar plate, as follows.

We wondered if some unknown contaminant(s) contained in agar powder was responsible for induction of conjugation. We examined this possibility by the following experiment. Agar powder (Wako, Osaka, Japan) was suspended in APW and kept at $4{ }^{\circ} \mathrm{C}$ under stirring overnight. After centrifugation $(185 \times g, 10 \mathrm{~min})$, resultant pellet was washed 2 times with APW by centrifugation. Final agar pellet was suspended in fresh APW and plates were prepared. Conjugation was successfully induced on this agar plate. When algal filaments were incubated in supernatant obtained by washing agar powder, conjugation was not induced at all (data not shown). Thus, incubation on agar plate but not soluble contaminant was responsible for induction of conjugation.

Since APW did not contain nitrogenous chemicals, agar plate should contain no or very few nitrogen. Therefore, it was possible that both factors, location on agar plate and depletion of nitrogen, worked synergistically in the induction. To examine this possibility, we incubated filaments on agar plate prepared using APW supplemented with $1 \mathrm{mM} \mathrm{KNO}_{3}$. On this agar plate, conjugation was also induced (Fig. 1a), indicating that depletion of nitrogen is not responsible for induction of conjugation. Furthermore, 

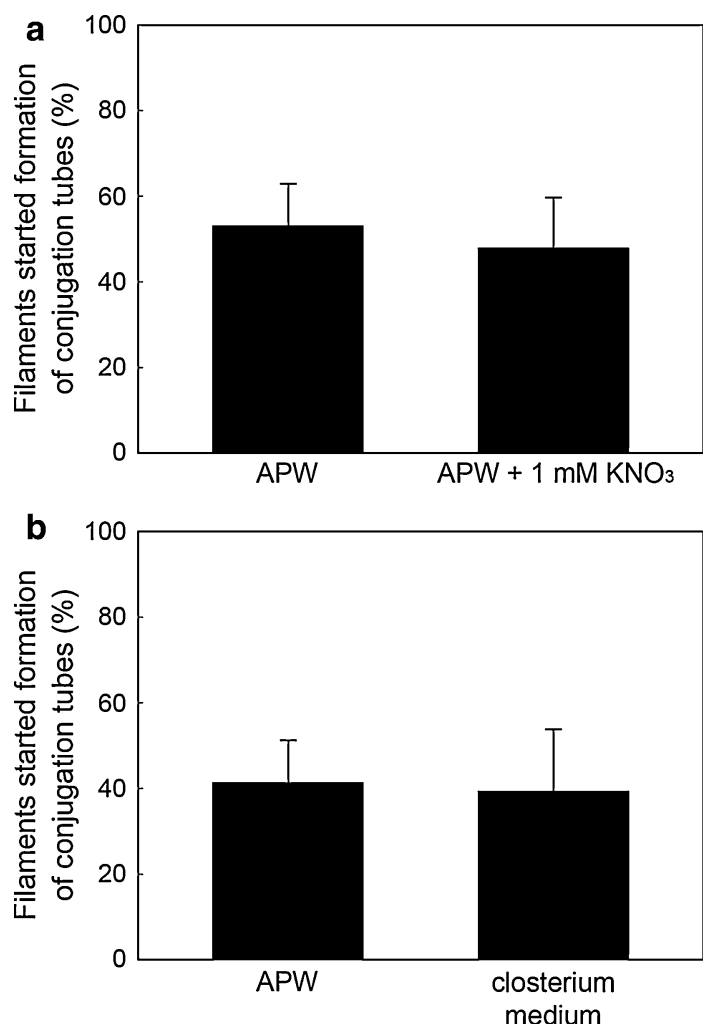

Fig. 1 Effect of $\mathrm{KNO}_{3}$ and closterium medium on start of conjugation on agar plate. About 100 filaments were incubated on agar plates prepared using APW, APW supplemented with $1 \mathrm{mM} \mathrm{KNO}_{3}$ or closterium medium at $23^{\circ} \mathrm{C}$ under a $12: 12 \mathrm{~h} \mathrm{~L}-\mathrm{D}$ cycle for 4 days. When papilla was observed, we judged that the cell started conjugation. Results were presented as a ratio of filaments started formation of conjugation tube to the total number of filaments. Experiments were repeated 3 times and the data are represented as the mean and standard error of the mean (SEM)

conjugation was induced when filaments were incubated on agar plate prepared using closterium medium, which contained various nutrients (Fig. 1b). These results unequivocally indicated that location on agar plate per se is a factor responsible for induction of conjugation.

Induction of conjugation on agar plate was examined in other species, S. fuluviatilis, which differentiated rhizoid upon cutting the algal filaments (data not shown) as in the case of $S$. castanacea. In this species, conjugation was also induced upon incubation on agar plate prepared using APW. We further examined conjugation on agar plate in three Spirogyra, which did not differentiate rhizoid. S. ellipsospora Transeau has been maintained in the laboratory as a contaminant of Chara culture. Other two Spirogyra sp. collected from Lake Biwa were maintained as axenic culture for 6 months. All three Spirogyra did not show conjugation by incubation on agar plate.

In some Spirogyra species, conjugation was induced by lowering or depletion of nitrogen content (Grote 1977; Yamashita and Sasaki 1979; Simons et al. 1984). In addition to nitrogen content, light intensity and/or $\mathrm{pH}$ had to be controlled in S. majuscule (Grote 1977). In S. castanacea and $S$. fuluviatilis, incubation on the agar plate was effective and depletion of nitrogen was not necessary (present study). On the other hand, Agrawal and Singh (2002) reported that Spirogyra sp. did not start conjugation on $2-10 \%$ agar plate. This was similar to our results obtained in Spirogyra sp., which did not differentiate rhizoid. Thus, factors necessary for induction of conjugation are much variable among Spirogyra species. We wondered whether inhibition of growth was responsible for induction of conjugation on agar plate. During incubation on agar plate prepared using either APW or closterium medium, cells proliferated via cell division on both agar plates when cells did not start formation of papilla of conjugation tube. Thus, inhibition of growth was not a trigger of conjugation.

To examine the presence of mating type between filaments, monoclonal culture of $S$. castanacea was subjected to induction of conjugation. After $48 \mathrm{~h}$ incubation, two types of conjugation were found in the same filament (Fig. 2a-c). Figure $2 \mathrm{~b}$ shows cells induced scalariform conjugation (arrowhead in Fig. 2a). On the other hand, Fig. $2 \mathrm{c}$ shows cells induced lateral conjugation (arrow in Fig. 2a). Zygospores were normally formed after the lateral conjugation (Fig. 2d). Yamagishi (1977) reported that the scalariform conjugation is generally observed, while lateral was rarely in $S$. castanacea. Our result was consistent with that of Yamagishi (1977). However, within a limit of our knowledge, induction of both scalariform and lateral conjugations in a same filament (Fig. 2a) is the first report. When two filaments paired, all cells of one filament behaved as male and those of other filament did as female in most cases. Very rarely, however, zygospores were formed in both filaments (Fig. 3). Thus, mating type is not fixed at least in S. castanacea. Hypnozygote was formed by incubation on the agar plate for about 1 month. However, it was difficult to reproducibly induce germination by adding closterium medium to them. Method to reproducibly induce germination must be found.

We examined identification of extracellular materials secreted during mating process using various lectins in S. castanacea. Among 19 lectins examined (BSL-I, BSL-II, Con A, DBA, DSL, ECL, jacalin, LEL, PHA-E, PHA-L, PNA, PSA, RCA I, SBA, SJA, STL, UEA I, VVL and WGA), BSL-1, Con A, jacalin, RCA-I and SBA stained reproductive cells but not vegetative cells (Table 1). Yoon et al. (2009) reported that three lectins, Con A, RCA and UEA, showed considerable labeling on extracellular materials in $S$. varians (Hassall) Kützing. Thus, lectinbinding materials secreted during conjugation seem different to some extent among species. We previously reported that BSL-I and jacalin showed contrasting stain patterns in rhizoid: jacalin clearly stained the outline of 
Fig. 2 Induction of both scalariform and lateral conjugations in the same filament. a Both scalariform and lateral conjugations were formed in the same filament after $48 \mathrm{~h}$ incubation. b Higher magnification of cells showing scalariform conjugation in a (arrow head). c Higher magnification of cells showing lateral conjugation in a (arrow). d Zygospores formed via lateral conjugation after $96 \mathrm{~h}$ incubation. Bars $50 \mu \mathrm{m}$

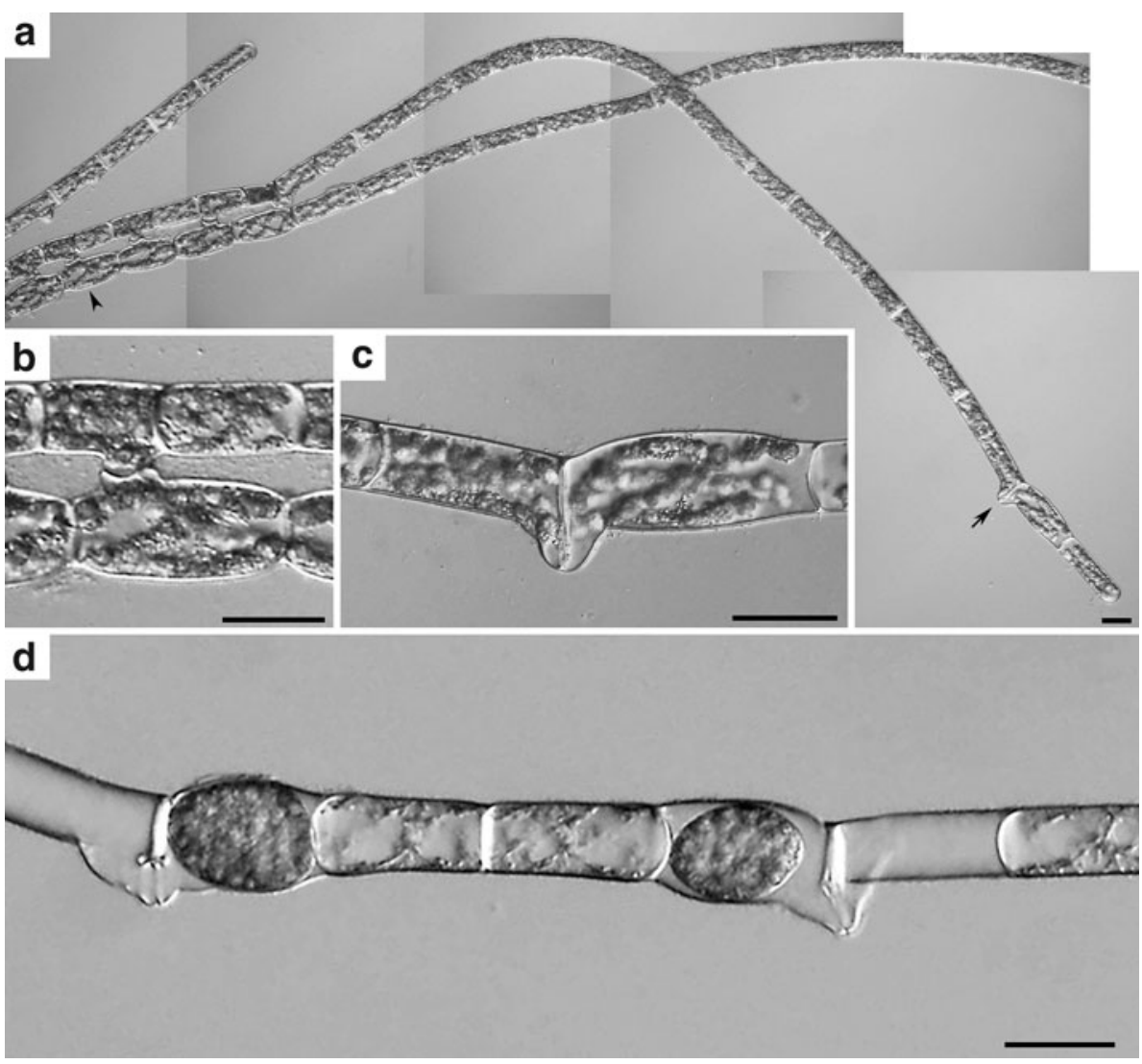

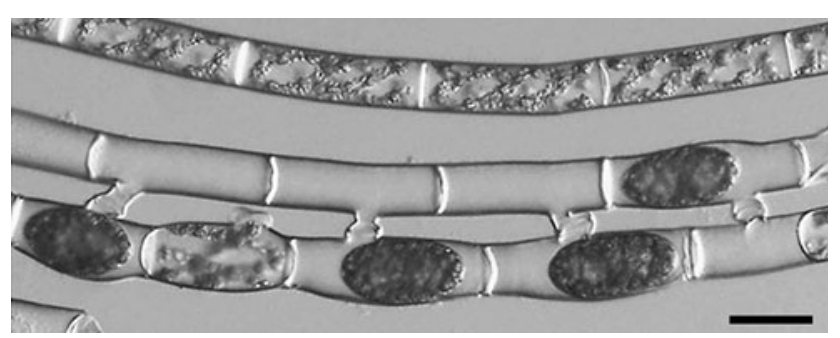

Fig. 3 Conjugation in clone culture. After $96 \mathrm{~h}$ incubation on agar plate, zygotes were formed. Zygospores were formed in both filaments. Bar $50 \mu \mathrm{m}$

rhizoid, while staining with BSL-I was diffused (Inoue et al. 1999, Ikegaya et al. 2008b). It was suggested that the BSL-I-binding material was responsible for adhesion of filaments to the substratum. On the other hand, the jacalinbinding material was speculated to be involved in recognition of substratum (Ikegaya et al. 2008b). In the present study, therefore, we focused our attention on BSL-I and jacalin (Fig. 4). After $48 \mathrm{~h}$ incubation on agar plate, a filament shown in Fig. 4a formed papillae in various directions. It was speculated that this filament started formation of papillae in the absence of the partner filament. BSL-I strongly stained surface of papillae. Septa between cells were also strongly stained. Next, we stained a pair of filaments started conjugation after $48 \mathrm{~h}$ incubation. In
Table 1 Survey of various lectins for binding to vegetative and reproductive cells of Spirogyra castanacea

\begin{tabular}{llll}
\hline Lectins & $\begin{array}{l}\text { Vegetative } \\
\text { cells }\end{array}$ & $\begin{array}{l}\text { Reproductive } \\
\text { cells }\end{array}$ & Specificity \\
\hline BSL-I & $\times$ & 0 & Gal $\alpha$, GalNAc $\alpha$ \\
Con A & $\times$ & 0 & Man $\alpha$, Glc $\alpha$ \\
Jacalin & $\times$ & 0 & Sialyl-Gal $\beta 1-3$ \\
& & & GalNAc- $O-$ \\
RCA I & $\times$ & 0 & Gal, GalNAc \\
SBA & $\times$ & 0 & GalNAc \\
WGA & $\times$ & $\times$ & (GlcNAc)n, sialic acid
\end{tabular}

Cells were stained $(O)$, not stained at all $(x)$

Fig. 4b, it was judged that upper filament was male gamete and that lower was female gamete, respectively, since diameter of lower cells of filament becomes larger than those of upper filament. Conjugation tubes elongated from paired cells were strongly stained, while whole cell surface of the female gamete was weakly stained (Fig. $4 b^{\prime}$ ). After $72 \mathrm{~h}$ incubation, whole cell surface of the male gamete was also weakly stained (Fig. $4 \mathrm{c}^{\prime}$ ). After $96 \mathrm{~h}$ incubation on agar plate, zygospores were formed (Fig. 4d). The conjugation tubes were strongly stained (Fig. $4 \mathrm{~d}^{\prime}$ ), while the surface of zygospores was not stained. Next, staining with jacalin was examined. Cells of filaments in Fig. 3e formed 
Fig. 4 Staining of filaments in the process of sexual reproduction with BSL-I and jacalin. Filaments incubated on agar plate were stained with either fluorescein-labeled BSL-I or jacalin $\left(\mathbf{a}^{\prime}-\mathbf{h}^{\prime}\right)$. Bright field microphotographs are also shown (a-h). $\mathbf{a}^{\prime}-\mathbf{d}^{\prime}$ staining with BSL-I. After $48 \mathrm{~h}$ incubation on the agar, papillae were formed in various directions $\left(\mathbf{a}, \mathbf{a}^{\prime}\right)$, or filaments started conjugation (b, $\mathbf{b}^{\prime}$ ). Conjugated filaments after $72 \mathrm{~h}$ incubation (c, $\left.\mathbf{c}^{\prime}\right)$. After $96 \mathrm{~h}$ incubation, zygotes were formed $\left(\mathbf{d}, \mathbf{d}^{\prime}\right) . \mathbf{e}^{\prime}-\mathbf{h}^{\prime}$ staining with jacalin. After $48 \mathrm{~h}$ incubation on the agar, papillae were formed in the same direction $\left(\mathbf{e}, \mathbf{e}^{\prime}\right)$, or filaments started conjugation $\left(\mathbf{f}, \mathbf{f}^{\prime}\right)$. Conjugated filaments after $72 \mathrm{~h}$ incubation $\left(\mathbf{g}, \mathbf{g}^{\prime}\right)$. After $96 \mathrm{~h}$ incubation, zygotes were formed (d, $\left.\mathbf{d}^{\prime}\right)$. Bar $50 \mu \mathrm{m}$
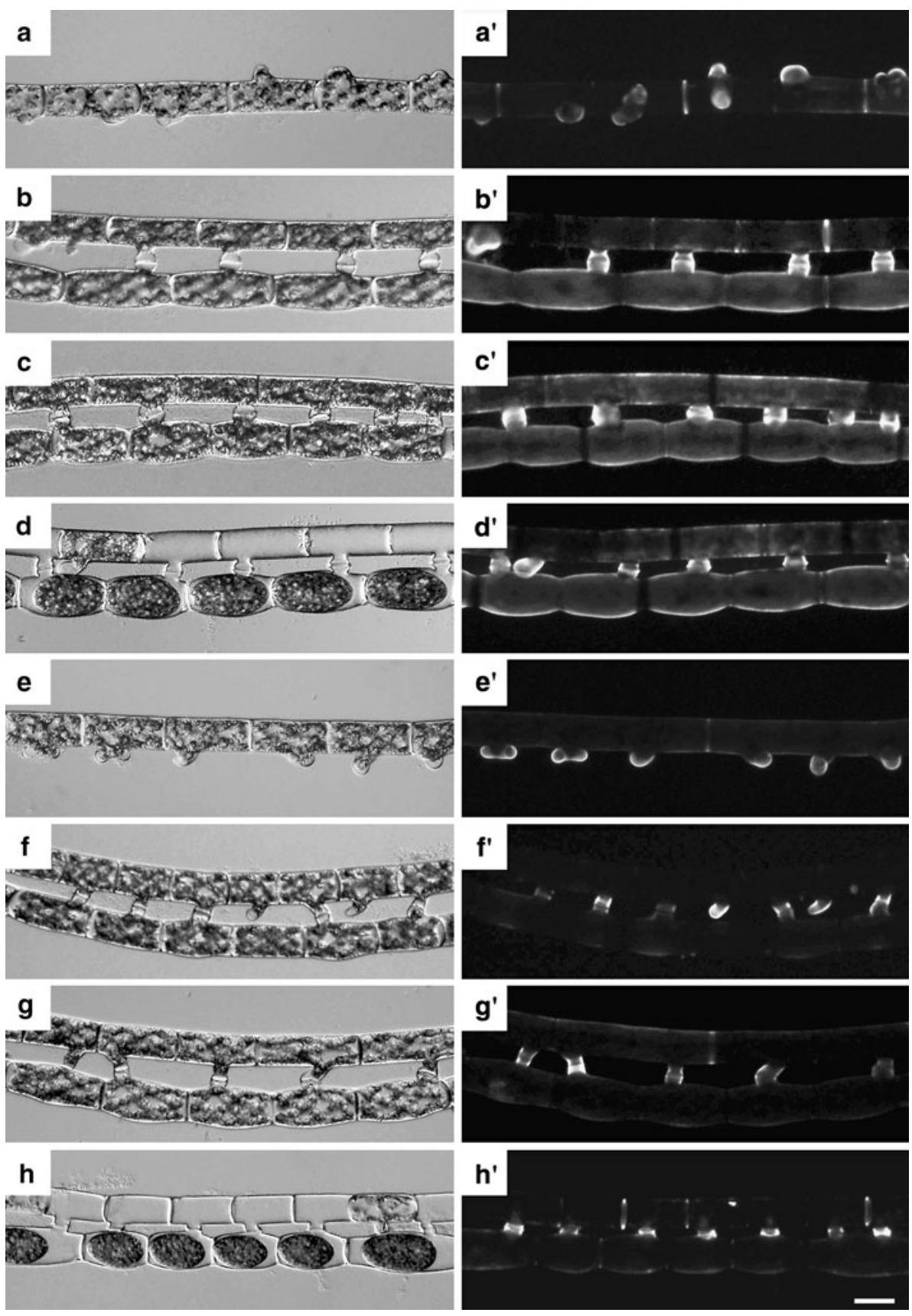

papillae in the same direction. We speculated that this filament started conjugation in the presence of a partner filament and it was lost during transfer onto the slide glass. Papillae were strongly stained with jacalin (Fig. 4e'). Throughout the process of conjugation, jacalin mainly stained the conjugation canals (Fig. $4 \mathrm{f}^{\prime}-\mathrm{h}^{\prime}$ ). The staining pattern with Con A, RCA-I and SBA was also examined (data not shown). Con A strongly stained the septa between the zygospore formed in female gamete, while papillae were very weakly. When zygospores were formed, the pattern of staining with either RCA-I or SBA was similar to that of BSL-I as shown in Fig. $4 \mathrm{~d}^{\prime}$.
We examine the effect of six lectins, BSL-I, Con A, jacalin, RCA-I, SBA, and WGA, on conjugation. Filaments were pre-incubated in APW supplemented with either one of lectins for 1 day. Then, they were transferred on agar plate supplemented with the same lectin and incubated for 4 days. It was found that jacalin severely inhibited the formation of zygospore, but others did not (data not shown). Systematic analysis showed that jacalin severely inhibited the step of the very beginning; start of papilla formation (Fig. 5). Next, reversibility of inhibition by jacalin was examined. Filaments were successively incubated in APW supplemented with jacalin for 1 day and 


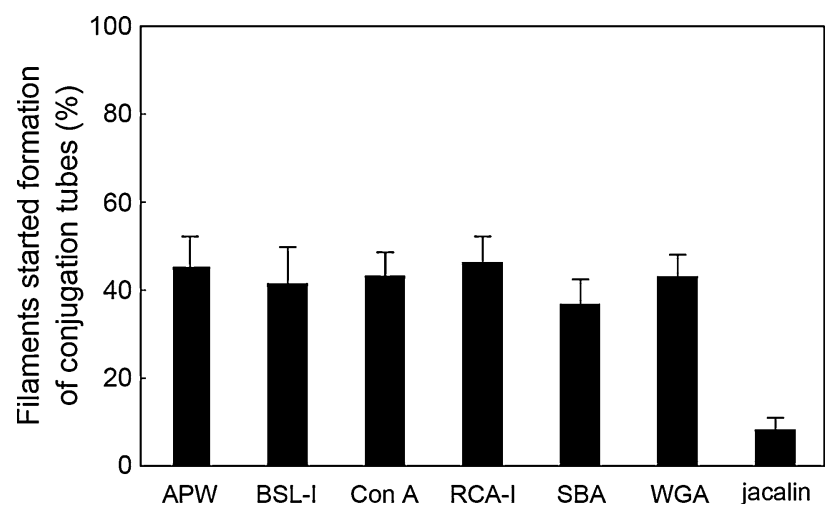

Fig. 5 Effect of lectins on start of conjugation tube formation. About 100 filaments were incubated in APW supplemented with either $1 \mu \mathrm{g} / \mathrm{ml}$ BSL-I, Con A, jacalin, RCA-I, SBA, or WGA at $23^{\circ} \mathrm{C}$ under a 12:12 $\mathrm{h} \mathrm{L}-\mathrm{D}$ cycle for $1 \mathrm{day}$, and then they were transferred on agar plate supplemented with the same lectin and incubated for 4 days. When papilla was observed, we judged that the cell started conjugation. Results were represented as a ratio of filaments started formation of conjugation tube to the total number of filaments. Experiments were repeated 4 times and the data are represented as the mean and SEM

then in APW lacking jacalin for 1 day. Then, they were incubated on agar plate lacking jacalin for 4 days. However, papilla was not formed at all. This irreversible inhibition might be caused by strong binding of jacalin. Yoon et al. (2009) reported that RCA and UEA inhibited conjugation. However, they did not identify the step of the inhibition. Although BSL-I, RCA-I, Con A and SBA also stained the conjugation tube, they did not inhibit formation of it. The roles of materials recognized by either BSL-I, RCA-I or SBA is the target of future studies.

Randhawa (1959) suggested similarity of the conjugation processes and rhizoid formation: contact stimulus is involved. On the other hand, Kniep (1928) believed that the conjugation processes were essentially due to a chemical stimulus (cited in Randhawa (1959)). Both conjugation tube and rhizoid start via formation of papilla and may elongate via tip growth. However, conjugation tube is formed at the flank but rhizoid is formed at the distal end of the cell (Nagata 1973). Jacalin clearly stained the outline of both conjugation tube (Fig. $3 \mathrm{e}^{\prime}-\mathrm{h}^{\prime}$ ) and rhizoid (Ikegaya et al. 2008b). Jacalin did not inhibit formation of rhizoid but inhibited differentiation to be rosette-shaped rhizoid (Ikegaya et al. 2008b). In the case of conjugation tubes, however, jacalin inhibited formation of papilla per se (Fig. 5). It seems that the role of jacalin-binding material is different in conjugation tube and rhizoid.

Success in reproducible induction of conjugation in the laboratory opened a way for systematic analyses of conjugation in Spirogyra, such as determination mechanism of sexuality of cells, role of lectin-binding materials, movement mechanism of male protoplast.
Acknowledgments We appreciate Dr. H. Nozaki (University of Tokyo, Japan) for his help in identifying $S$. castanacea. We also thank Dr. Y. Tominaga (St. Agnes' Junior College, Japan) and Dr. H. Yano (Research Institute for Sustainable Humanosphere, Kyoto University) for invaluable discussion.

Open Access This article is distributed under the terms of the Creative Commons Attribution Noncommercial License which permits any noncommercial use, distribution, and reproduction in any medium, provided the original author(s) and source are credited.

\section{References}

Agrawal SC, Singh V (2002) Viability of dried filaments, survivability and reproduction under water stress, and survivability following heat and UV exposure in Lyngbya martensiana, Oscillatoria agardhii, Nostoc calcicola, Hormidium fluitans, Spirogyra sp. and Vaucheria geminata. Folia Microbiol 47:61-67

Allen MA (1958) The biology of a species complex in Spirogyra. $\mathrm{Ph} . \mathrm{D}$. thesis, Indiana University, Bloomington

Cheli F, De Vecchi L (1989) An ultrastructural and cytochemical study on conjugatophycean cell wall. Caryologia 42:127-138

Grote M (1977) Untersuchungen zum Kopulationsablauf bei der Grünalge Spirogyra majuscula. Protoplasma 91:71-82

Hull HM, Hoshaw RW, Wang JC (1985) Interpretation of zygospore wall structure and taxonomy of Spirogyra and Sirogonium (Zygnemataceae, chlorophyta). Phycologia 24:231-239

Ichimura T (1971) Sexual cell division and conjugation-papilla formation in sexual reproduction of Closterium strigosum. In: Nishizawa K (ed) Proceedings of the 7th International Seaweed Symposium. University of Tokyo Press, Tokyo, pp 208-214

Ikegaya H, Yamada S, Sonobe S, Shimmen T (2004) Saponin-induced release of single cells from filaments and rhizoid differentiation in Spirogyra. J Plant Res 117:443-447

Ikegaya H, Hayashi T, Kaku T, Iwata K, Sonobe S, Shimmen T (2008a) Rhizoid differentiation and xyloglucan-like polysaccharides in Spirogyra. Phycol Res 56:216-222

Ikegaya H, Sonobe S, Shimmen T (2008b) Rhizoid differentiation of Spirogyra is regulated by substratum. J Plant Res 121:571-579

Inoue N, Sonobe S, Nagata Y, Shimmen T (1999) Secretion of lectinbinding material in rhizoid differentiation of Spirogyra. Plant Cell Physiol 40:973-977

Inoue N, Yamada S, Shimmen T (2002) Rhizoid differentiation in Spirogyra: position sensing by terminal cells. Plant Cell Physiol 43:479-483

Iwata K (1995) Regulation of the orientation of cortical microtubules in Spirogyra cells. J Plant Res 108:531-534

Iwata K, Itoh T (1998) Effect of ions on the orientation of cortical microtubules in Spirogyra cells. Plant Cell Physiol 39:1099-1103

Iwata K, Tazawa M, Itoh T (2001) Turgor pressure regulation and the orientation of cortical microtubules in Spirogyra cells. Plant Cell Physiol 42:594-598

Jordan EG (1974) Nuclear envelope projections from pronuclei of Spirogyra zygotes. Protoplasma 79:31-40

Kadlubowska JZ (1984) Conjugatophyceae I: Zygnemales. In: Ettl H, Gerloff H, Heynig H, Mollenhauer D (eds) Süßwasserflora von Mitteleuropa, Chlorophyta VIII. Gustav Fischer Verlag, Stuttgart

Kniep H (1928) Die Sexualitiit der niederen Pflanzen. Jena

Lloyd FE (1924) Some effects of narcotics on Spirogyra. Anesth Analg 3:9-19

Lloyd FE (1926a) Maturation and Conjugation in Spirogyra longata. Trans R Can Inst 15:151-195 
Lloyd FE (1926b) Studies on Spirogyra. Trans R Soc Can 5:75-110 Nagata Y (1973) Rhizoid differentiation in Spirogyra. I. Basic features of rhizoid formation. Plant Cell Physiol 14:531-541

Ogawa S (1982) Disintegration of chloroplasts during zygote formation in Spirogyra verruculosa. Bot Mag Tokyo 95:249-260

Pringsheim EG (1946) The biphasic or soil-water culture method for growing algae and flagellata. J Ecol 33:193-204

Randhawa MS (1959) Zygnemaceae. Indian Council of Agricultural Research, New Delhi

Sasaki K, Takaya K, Ueno T (1972) Suppression of nucleic acid synthesis in chromatin of Spirogyra during conjugation process. Plant Cell Physiol 13:601-608

Saunders H (1932) Conjugation in Spirogyra. Ann Bot 45:233-256

Simons J, Van Beem AP, de Vries PJR (1984) Induction of conjugation and spore formation in species of Spirogyra, Chlorophyceae, Zygnematales. Acta Bot Neerl 33:323-334

Yamada S, Sonobe S, Shimmen T (2003) Synthesis of a callosic substance during rhizoid differentiation in Spirogyra. Plant Cell Physiol 44:1225-1228

Yamagishi T (1977) Illustrations of the Japanese fresh-water algae. In: Hirose $\mathrm{H}$, Yamagishi $\mathrm{T}$ (eds) Uchida Roukakuho Publishing Co., LTD., Tokyo, pp 416-461
Yamashita T, Sasaki K (1979) Conditions for the induction of the mating process and changes in contents of carbohydrates and nitrogen compounds during the mating process of Spirogyra. J Fac Sci Hokkaido Univ Ser Bot 11:279-287

Yoon M, Kim MY, Kim GH (2009) Conjugation process in Spirogyra varians monitored with FITC-lectins (Zygnemataceae, Chlorophyta). Algae 24:39-45

Yoshida K, Shimmen (2007) Role of orientation of cellulose microfibrils in rhizoid differentiation of Spirogyra. Plant cell Physiol 48:S111

Yoshida K, Shimmen T (2009) Involvement of actin filaments in rhizoid morphogenesis of Spirogyra. Physiol Plant 135:98-107

Yoshida K, Inoue N, Sonobe S, Shimmen T (2003) Involvement of microtubules in rhizoid differentiation of Spirogyra species. Protoplasma 221:227-235

Yoshida K, Horikawa Y, Itoh T, Shimmen T (2006) Control of cellulose microfibril orientation by cortical microtubules in Spirogyra. Plant Cell Physiol 47:S192

Yoshida K, Ohtani A, Mimura T, Shimmen T (2008) Adjustment of osmotic pressure coupled with change of growth mode in Spirogyra. Funct Plant Biol 35:580-584 